\title{
A CRISE FINANCEIRA MUNDIAL, O ESTADO E A DEMOCRACIA ECONÔMICA
}

\author{
Gabriel Real Ferrer \\ Paulo Márcio Cruź
}

\section{RESUMO}

Os problemas vividos na atualidade, principalmente a grave situação financeira internacional, significam sinal evidente de insuficiência do modelo teórico moderno. Talvez sustentem a própria crise do Estado Constitucional Modemo. Alguns exemplos recentes parecem comprovar tal crise: o complexo de indústrias mundiais de alimentos que arrasa sementes tradicionais acabou por criar uma situação de desequilíbrio alimentar no planeta. Além disso, fatos como a comercialização mundial do petróleo, o monopólio da comunicação e a realidade virtual manipulável demonstram que a "internalização" do Poder Público da modernidade provavelmente cederá espaço para a transnacionalização desse mesmo Poder Público. Repensar, pois, a Democracia neste momento é fundamental, principalmente em sua vertente transnacional. Todo o mundo "acordado" e afetado pela globalização, faz-se cada vez mais certo que o único poder legítimo é o poder com investidura decidida pela maioria, que se constitui a partir de instrumentos democráticos efetivos.

Palavras-Chave: Crise financeira. Democracia. Estado Constitucional Moderno. Estado Transnacional. Transnacionalidade.

\section{A(s) Crise(s) - Considerações Introdutórias}

Enquanto este artigo é escrito, o mundo do capitalismo globalizado é sacudido pela maior crise financeira da história, fato que merece uma profunda reflexão. É, provavelmente, mais uma comprovação dos riscos apontados por Ulrich Beck ${ }^{3}$. Como o espaço público transnacional ainda está em fase de construção teórica, as nações assistem perplexas à derrocada do grande cassino global montado pelos Estados Unidos. Os países da Europa, que se esbaldaram jogando nesse cassino, afundam junto com a pretensa credibilidade e solidez do sistema financeiro norte-americano.

Os Estados Unidos e o mundo certamente sairão diferentes dessa crise, até em termos ideológicos, e adotarão mecanismos mais rígidos de controle financeiro. Não obstante, essas necessárias transformações provavelmente não abordarão de maneira consistente o problema caso se limitem a incorporar mecanismos que pretendam dotar, de maior segurança, o sistema e seus operadores. e esquecendo, que em sua raiz, se encontra um modo de entender as relações econômicas, baseadas exclusivamente no 
interesse individual, alimentando um desaforado afã de lucro e ignorando totalmente o interesse da maioria ${ }^{4}$.

Ainda que o tsunami financeiro, de modo imediato, haja afetado diretamente um bom número de operadores econômicos que basearam sua atividade e expectativas de benefício em movimentos especulativos, é certo que tal "onda" está atingindo setores essenciais da economia real, o que alterou de maneira muito negativa o modo de vida e a possibilidade de desenvolvimento pessoal e social de centenas de milhões de pessoas no planeta. Entre outros efeitos, a crise financeira pode implicar 20 milhões de pessoas desempregadas em todo o mundo até o final de 2009, conforme afirmou o diretor geral da OIT (Organização Internacional do Trabalho), Juan Somavía, em uma entrevista coletiva à imprensa.

Segundo as estimativas da OIT apresentadas por Somavía, o número de desempregados poderá subir de 190 milhões em 2007 para 210 milhões no final de 2009, e inclusive ser maior se a crise se agravar ${ }^{5}$. Não há, portanto, como não se discutir com profundidade teórica essa crise, especialmente no âmbito do Direito e da Teoria do Estado e, em geral, do Direito Público, pois essa é a única perspectiva que permitirá que os interesses gerais estejam presentes na nova ordem que é preciso construir.

O mundo acadêmico foi incapaz de prever essa crise e deve, ao menos, discutila na medida de sua gravidade. Ainda que seja uma ideia que aparece de modo recorrente quando se discutem problemas globais ${ }^{6}$, nunca esteve tão evidente a necessidade de se criar um espaço regulatório transnacional. No que compete mais especificamente à problemática em discussão, um estado que submeta 0 capital ao interesse da maioria dos habitantes do planeta.

A fim de lançar luz sobre esse impasse, a possibilidade de republicanização da globalização ${ }^{7}$ deve ser, sem dúvidas, uma questão central do grande debate que se avizinha e, portanto, um ótimo começo de discussão. Mas é o papel da Democracia o assunto que melhor representa as conseqüências possíveis para essa crise que transformou as bolsas de valores em pesadelos diários para as instituições financeiras e para boa parte dos habitantes do planeta.

Assim, as principais perguntas às quais se quer ajudar a responder com o presente artigo são: como será e que papel terá a Democracia Econômica no século $\mathrm{XXI}^{8}$, já que esta é uma das formas teóricas de Capitalismo Democrático? Adianta-se que os requisitos que podem satisfazer um projeto de democratização das relações econômicas são de dois matizes: primeiro, apresentar um "desenho global" da capacidade de persuadir aquelas pessoas que reconheçam valor nas políticas de inovação (de identidade e de solidariedade). Segundo, prever benefícios materiais que os indivíduos possam perceber imediatamente ou calculá-los com facilidade (incentivos materiais e individuais).

Os programas de Democracia Econômica podem, então, desenvolver a dupla função de mobilizar as paixões e os interesses - os dois matizes. Neste sentido, é 
importante a investigação que realiza Domenico Nuti $^{9}$, que parte da hipótese de que as diferentes acepções de Democracia Econômica - correção do funcionamento espontâneo do mercado através de políticas de intervenção do Poder Público a partir da constituição de instituições regulatórias de Governo Transnacional e valorização de diferentes âmbitos de Democracia Micro-Econômica - não são alternativas, mas sim instrumentos complementares à Democracia como valor. As pesquisas do autor italiano concluem que o processo de Democracia Econômica se desenvolve através de uma pluralidade de dimensões, que vão desde o econômico, passando pelo social e chegando ao fundamental fator ambiental.

Além de Domenico Nuti, outros autores apontam, de modo geral, que a Democracia Econômica pode ser associada a algumas dimensões. Uma delas estaria relacionada com a "superação dos modelos de industrialismo". Segundo esta visão, os programas de Democracia Econômica terão dificuldades para alcançarem êxito se não forem abertos à maioria dos trabalhadores e cidadãos. Considerando-se o modelo social-democrata sueco, que funciona como uma espécie de paradigma, a Democracia Econômica deve ser considerada a terceira etapa no desenvolvimento da Democracia e deverá assinalar a evolução desde as democracias política e social (que já estão razoavelmente discutidas, mas não implantadas, principalmente nos países ditos emergentes, como o Brasil) até a Democracia Econômica. A questão está, pois, ligada a todas as tentativas para ampliar e qualificar a cidadania ${ }^{10}$. É claro que um novo modelo de Poder Público, superados os conceitos clássicos de Soberania, Divisão de Poderes e Democracia Representativa, constituirá um fundamental meio de cultura para os projetos de Democracia Econômica.

Já a outra dimensão está vinculada com as reformas e funcionamento das relações industriais. 0 processo, muito provavelmente, será multidisciplinar, e aqui, no caso, economistas e administradores públicos e privados devem estar convencidos da premência da mudança, até para a própria sobrevivência da espécie humana. $\mathrm{Na}$ maioria dos países, existe uma crise crônica e desorientadora dos modelos clássicos do pluralismo e do neo-corporativismo. As relações empresariais mais eficazes são aquelas que combinam um bom grau de concentração com margens de descentralização, de regulação rigorosa com elementos de flexibilidade. $O$ rol de empresas interessadas só poderá se consolidar se estiverem presentes propostas de aumento de qualidade e a participação nos seus resultados e nas suas funções de coordenação e administração. ${ }^{11}$

Como se consegue perceber, é preciso ir fundo nas propostas de reforma dos fundamentos do Capitalismo. Caso não seja controlado pela Sociedade, qualquer tipo de tentativa de desenvolvimento de modelos de Poder Público Transnacional será efêmero, infrutífero. E o único modo talvez de convencer os centros de comando capitalistas é demonstrar que o futuro da humanidade e o do próprio capitalismo depende dessa mudança de concepção, fazendo convergir Democracia, lucro e interesse social transnacional para o bem comum.

Colocar esse tipo de questão pouco tempo depois de derrubado o mundo comunista pode soar como provocação ou um convite duvidoso à predição. Mas, 
mesmo que ninguém duvide que a queda do Muro de Berlin tenha marcado o final de uma época, deve-se precisar qual a época que terminou para se poder medir o verdadeiro alcance deste acontecimento e suas repercussões.

Os otimistas defendem que a época terminada começou em 1945. Em nome do combate pela Democracia, havia-se derrotado Hitler. $E$, não se pode esquecer, a derrota só se deu com a ajuda de Stalin, que cobrou uma conta bastante alta por isso: a servidão de metade da Europa ao comunismo. Quarenta e cinco anos mais tarde a vitória foi completa. Parece que foi ganha a batalha das idéias.

Quem hoje recorre a Lênin para questionar Montesquieu? Isso passou a ser coisa do passado, pois a evolução das idéias políticas havia alcançado sua última fase, e a República Liberal, herdeira do século XVIII e da filosofia ilustrada, representaria a forma mais perfeita de organização humana. A liberdade burguesa havia triunfado e se estaria perto do fim da história, se é verdade que a história, apesar de tudo, é a batalha das idéias. Francis Fukuyama e seu The end of history and the last man parecia ter razão $^{12}$.

Os pessimistas denunciaram essa interpretação, que julgaram simplista e ingênua. $O$ período que termina não começou em 1945, mas sim em 1917 . 0 parêntesis ideológico da revolução bolchevique estava encerrado e não se estaria assistindo ao final da história, mas sim ao retorno das nações. Nossa triunfante modernidade estaria ameaçada por um retrocesso histórico. Estar-se-ia obcecado pelo século XIX.

Sobre o conhecimento que se tem sobre essa interposição de épocas, esse artigo enseja uma hipótese muito mais ampla. $O$ ano de 1989 não encerra uma época iniciada em 1917 ou em 1945. Graças a $1789^{13}$, 1989 encerra o que se institucionalizou: a era do Estado Constitucional Moderno Soberano e endógeno. A era da modernidade político-jurídica caracterizada pela "justificação do político". Logo, o problema passou a ser que o âmbito do "político" transbordou inquestionavelmente dos estreitos limites do Estado Constitucional Moderno, mudando radicalmente.

Assim, depois de realizada uma revisão histórica de certas alterações políticoeconômicas, tornou-se inevitável verificar a obsolescência das instituições modernas e descobrir que, entre a era em que estamos entrando e as construções da Era das Luzes há mais diferenças do que entre esta e a era patrimonial que a havia precedido. Todavia, ainda será muito difícil admitir o esgotamento do Estado Constitucional Moderno, assim como será difícil abandonar o barco à deriva e semi-naufragado ${ }^{14}$. 0 desafio se coloca, porque não se conheceu mais nada diferente das categorias Democracia Representativa, Liberdade, Igualdade e Política, as quais ainda definem os horizontes do pensamento. Por outro lado, já não há segurança em conhecer significados de categorias cuja adesão deriva mais de um "ato reflexo" que da reflexão, propriamente dita.

Como escreve Ferrajoli ${ }^{15}$ vive-se hoje - e todos devem estar conscientes disso uma crise histórica não menos radical do que a que aconteceu com as revoluções 
burguesas do Século XVII. A potência destrutiva das armas nucleares, as agressões cada vez mais catastróficas contra 0 ambiente, o aumento das desigualdades sociais, a explosão dos conflitos étnicos fazem com que o equilíbrio planetário seja cada vez mais precário, e, portanto, que se torne mais difícil a conservação da paz. E agora a crise financeira.

Está-se chegando à conclusão de que os herdeiros da Era das Luzes são apoplécticos: as leis se converteram em receitas, o Direito em método e o Estado Constitucional Moderno em meros espaços jurídicos incapazes de enfrentar os desafios transnacionais. A grande questão a ser respondida é se isso é suficiente para assegurar o futuro da Democracia. Tem-se que perguntar, hoje, como será a Democracia sem soberania nacional. $O$ grande edifício da era moderna perdeu seus alicerces e flutua, livre de todas as amarras, abandonado a si mesmo, feito papel carregado pelo vento, como escreve Ferrajoli.

Por outro lado, parece ser um erro ver com temor o fim desta era. Seria um enorme erro ver o Estado Constitucional Moderno como um fim em si mesmo. A organização política herdada da Idade das Luzes representa só um episódio da história humana, o meio que foi encontrado, numa certa etapa de seu desenvolvimento, para fundamentar a liberdade numa ordem política.

No momento atual a Sociedade Mundial está carente de um upgrade civilizatório. As últimas gerações humanas são devedoras de um efetivo novo avanço do que se pode chamar de um mundo solidário e humanizado. A modernidade caracterizou um significativo avanço, apesar de um avanço baseado no individualismo. 0 mundo atual é complexo demais para seus obsoletos paradigmas teóricos.

Deve-se compreender que esta nova era não deve ser combatida - seria trabalho inútil - e sim ser objeto de novas teorizações, que possam conduzir a humanidade ao seu episódio seguinte, sempre com a perspectiva de uma evolução positiva $^{16}$.

O ser humano, dono de inteligência e diferente dos outros animais, está no planeta, provavelmente, para provar que pode sobreviver sem estar no estado de natureza, que é possível viver em uma organização política democrática adstrita aos paradigmas de participação, da política de tolerância, da distribuição da riqueza, da utilização sustentável do meio ambiente, da solidariedade e da diversidade e do sociatismo $^{17}$, não necessariamente nessa ordem.

Para isso é preciso entender que o capitalismo "solto" e "desteorizado" formou uma tecno-estrutura que é uma rede global que nada tem a ver com livre mercado, já que este está baseado em um sistema mundial assentado sobre cinco monopólios ${ }^{18}:$ I O monopólio das finanças, baseado no padrão dólar dos Estados Unidos da América e nas políticas do Banco Mundial e do Fundo Monetário Internacional. 0 monopólio das finanças faz da economia financeira especulativa um vírus que está destroçando - ou já destroçou - as economias produtivas, fazendo com que os trilhões de dólares que circulam diariamente nos principais centros financeiros superem em mais de duas 
vezes as reservas dos bancos centrais dos países que compõem a Organização para Cooperação e Desenvolvimento Econômico ${ }^{19}$ - OCDE. Mesmo com o Euro, é importante dizer, essa realidade permanece praticamente intacta; II - O monopólio tecnológico, que atua, principalmente, sobre as patentes e direitos de propriedade, atentando gravemente contra a biodiversidade das espécies. $O$ complexo de indústrias mundiais de alimentos controla cada vez mais as "variedades de alto rendimento" e arrasa as culturas de sementes tradicionais; III - O monopólio energético, que atua sobre os recursos naturais e, especialmente, sobre o petróleo, através de sua comercialização mundial e por meio dos países intermediários. Desta maneira, os preços do petróleo podem ser controlados e o dinheiro utilizado na sua compra recuperado via mercado financeiro para investimentos nos países ricos; IV - 0 monopólio da comunicação, que faz com que, cada vez mais, a realidade seja virtual e manipulável, já que, através dos meios de informação, podem convencer a todos de que a verdade é a verdade que lhes convém; $\mathbf{V}$ - 0 monopólio militar, que, como foi demonstrado nas guerras do Golfo e na invasão do Iraque, tem relação intrínseca com os monopólios citados anteriormente, formando uma estrutura integrada. Por estes conflitos, pode-se exemplificar tanto a capacidade de violência física como sua relação com os monopólios de recursos naturais, comunicativos, tecnológicos e financeiros, e suas lógicas relações internas.

Caso não se possa, teórica e praticamente, ajustar o Poder Público de modo que ele possa atuar para impedir que esta tecno-estrutura mundial concentre riqueza e ameace a própria vida no planeta, o futuro estará ameaçado. Como aponta Tomas Villasante ${ }^{20}$, a "intemalização" do Poder Público da modernidade provavelmente cederá passo ao processo de transnacionalização do Poder Público. Caso contrário, a debilidade do Estado Constitucional Moderno poderá conduzir a civilização a perigosas posições de confronto e autodestruição. ${ }^{21}$

Está-se vivendo uma acelerada etapa de transição a novas formas de organização, em escala planetária. É importante ter-se consciência de que, na configuração da nova ordem mundial, a Democracia deverá desempenhar um papel mais importante que o Estado Constitucional Modemo, mesmo que, algumas vezes, pareça ser o contrário.

Esse novo papel prevê que a globalização do mercado e das tecnologias da informação deve estar acompanhada de uma globalização política e social, na qual os valores democráticos tenham um claro protagonismo. Esta é a única via, se a intenção é tratar de uma globalização que beneficie a todos e que não seja meramente quantitativa, mas principalmente qualitativa. Uma globalização que seja assumida como uma nova maneira de estar no mundo e que implique, portanto, novo estilo de vida. Um estilo para todos, com comunhão de civilizações e não o choque delas, como explica Samuel Huntington ${ }^{22}$.

A globalização só terá sentido e será verdadeiramente universal se for capaz de estruturar e criar um conjunto de relações de um novo tipo. Um mundo globalizado pressupõe novas relações de interdependência, novas necessidades e, por que não, novos problemas. Pressupõe ainda novos sujeitos capazes de fazer frente aos desafios 
globais. A reconstrução da Sociedade pós Estado Constitucional Moderno passa pela reabilitação do político, do social e do cultural contra a hegemonia da razão econômica ${ }^{23}$. Isso implica uma redefinição ou, mais exatamente, um redescobrimento do bem comum, de um saber-viver juntos e de um novo sentido para a aventura de viver.

É possível que haja o entendimento de isso seja uma utopia. Também não se está pensando que tratar de um assunto com esta capacidade para gerar polêmica será fácil. Mas o que é certo é que não se pode continuar por mais tempo nessa "racionalidade irracional" em que está mergulhado o mundo atual. Está-se diante de uma singular oportunidade histórica: configurar um Poder Público que possa ser aplicado ao local, ao regional e ao mundial, que seja sensível ao ser humano e propenso a incluir todas as pessoas a um mínimo de bem-estar.

Urge perceber que a ausência do político está permitindo que as grandes corporações multinacionais levem a cabo, na prática, uma autêntica tomada do poder, um verdadeiro controle do mundo à margem da política. Sob o véu de uma pretensa racionalidade econômica e por trás de uma aparência formal de apoliticidade, está-se desenvolvendo, na prática, com extraordinária força, um novo tipo de política, que pode ser qualificada como "parapolítica". Essa atividade "parapolítica", gerada a partir dos centros financeiros, está permitindo que as corporações globais ocupem os centros materiais vitais da Sociedade, de forma imperceptível, sem revolução, sem mudanças na lei nem nas constituições, através do simples desenvolvimento da vida cotidiana. Por conseqüência, os cidadãos estão sendo jogados a um mundo de redes anônimas, no qual as empresas multinacionais se transformam no modelo de conduta.

A nova utopia prevê, por outro lado, a existência de uma integração entre o mercado da informação e o da comunicação, graças às redes eletrônicas e de satélites, sem fronteiras, funcionando em tempo real e de forma permanente.

Assim, a globalização pode ajudar em três sentidos: poder fazer evidente a interdependência; ter despertado o pluralismo da diversidade e ter ampliado a várias camadas da população mundial a sensação de pertencer a uma realidade transnacional e, também, transestatal, capaz de despertar os vínculos de solidariedade imprescindíveis para a emergência de uma sociedade global, algo a que a humanidade nunca assistiu ${ }^{24}$.

\section{A(s) Democracia(s)}

O sistema mundial atual é um produto do capitalismo industrial transnacional que integra em si tanto setores pré-industriais, como setores pós-industriais. Então, a utopia de uma Sociedade mais justa e de uma vida melhor somente poderá prosperar com a inserção dos princípios democráticos nas práticas capitalistas; uma idéia que, sendo utopia, é tão necessária quanto o próprio capitalismo. ${ }^{25}$ 
Em que pese o desaparecimento das fronteiras que separavam os sistemas políticos em função de sua adesão a modelos econômicos antagônicos, continua tendo uma elevada dose de atualidade o problema da relação entre Democracia e economia de mercado. $O$ problema está na possível incompatibilidade entre a "autodeterminação do Estado" - como reflexo teórico, por sua vez, da vontade da maioria popular soberana - e o poder financeiro e econômico das grandes corporações empresariais. Essa dialética ganha maior intensidade se considerado esse muito conhecido fenômeno denominado globalização, que vem confirmar a subordinação do Estado Constitucional Moderno às decisões adotadas nos circuitos econômicos que formam as grandes multinacionais e os mercados financeiros, nos quais o protagonismo está a cargo de instituições bancárias com um considerável nível de independência com relação aos ambientes democráticos.

Esta realidade está na pauta da doutrina mais avançada, que entende serem necessários esforços para democratizar o capitalismo e torná-lo solidário, superando a idéia de acumulação individual, ou de grupos, em detrimento do conjunto da Sociedade global.

Repensar a Democracia neste momento histórico significa fazê-lo a partir de um pluralismo que possui duas vertentes: a pluralidade de atores que disputarão a governabilidade mundial e que romperão o paradigma da endogenia estatal moderna, e a pluralidade de culturas que exigem que a liberdade seja vivida a serviço da inclusão social e que a igualdade seja vivida a serviço da diferença. Isto implica, claramente, ir muito mais além do modelo de Democracia representativo liberal.

A teoria da Democracia não tem que ser necessariamente reinventada, mas, certamente, tem de se reorientar. O termo "repensar" deve ser entendido como um intento para captar e centrar os novos problemas de uma história que virou uma página e que volta a começar. Trata-se de algo diferente do fim da história. Ao contrário do que sustenta Fukuyama, está-se diante de um futuro denso de incógnitas e seguramente muito distinto do presente que se conhece. Para tanto, será necessária uma boa dose de valentia e esperança diante de um futuro que, em boa medida, estará nas mãos daqueles que se proponham a teorizar um novo Poder Público, para depois do Estado Constitucional Modemo.

Seja como for, e seja qual for o "cimento" das vidas em comunidades políticas comuns - língua, costume, cultura, religião ou, até, etnia - o mundo do Século XXI já não crê na legitimidade que não seja verdadeiramente democrática.

Hoje, embora sua gravidade não seja totalmente reconhecida, está-se presenciando uma crise profunda não deste ou daquele setor, mas do próprio modelo de civilização da modernidade.

É importante destacar que as premissas básicas dos revisionistas democráticos falharam: a elite não defende valores democráticos, mas antes instituições oligárquicas; mais freqüentemente do que o seu apoio às elites autoritárias, os movimentos de massa defendem direitos democráticos e mudanças que contrariam os interesses das 
elites (direitos civis, femininos, ecologia, trabalho). James Petras ${ }^{26}$ assinala, a propósito, que sociedades complexas são mais dificilmente compreendidas por elites que defendem conjuntos estreitos de interesses privados.

Assim, é importante destacar que, para a Democracia funcionar no ambiente atual, é preciso rever mentalidades e atitudes e não métodos ou procedimentos. Como escreve Arnaldo Miglino ${ }^{27}$, a Democracia não pode ser apenas uma forma de se proceder. Ela é, acima de tudo, um valor que pressupõe a aplicação de outros princípios, como o da liberdade de expressão e opinião, o da liberdade de obtenção de informação imparcial e correta e o da publicidade dos fatos que se referem à esfera pública. Considerando-se que um dos momentos fundamentais da Democracia é a escolha dos governantes, seria impossível, de maneira eficaz, que o povo pudesse fazer uma escolha do gênero sem gozar da liberdade intelectual e sem poder dispor de informações sobre a realidade.

A categoria "Democracia" não é utilizada aqui no sentido da teoria sistêmica, na esteira do que pensa Friedrich Müller ${ }^{28}$, mas no do Direito Público e da Teoria do Estado. Diz respeito, portanto, a todas as normas, estruturas, objetivos e valores essenciais de um Estado - ou de um espaço público transnacional - que se possa denominar "democrático". Também se esclarece que a categoria "Exclusão Social"29 não diz apenas respeito à pobreza ou marginalização, mas à conhecida e fatal "reação em cadeia da exclusão", que se materializa pela exclusão econômico/financeira e até pela exclusão jurídica (negação da proteção jurídica e dos direitos humanos, etc.), passando pela exclusão social, cultural e política. São valores que, ao contrário, impedem que um Estado possa ser denominado de democrático.

A Democracia não está livre do perigo da destruição - da autodestruição. Isso porque a Democracia encontra-se, paradoxalmente, em contradição com a necessidade desse sentimento de pertencer à comunidade. A Democracia Representativa Moderna é um sistema frio. Está constituída por princípios, regras e instituições. Mas sua existência depende do esforço e do engajamento do cidadão. Assim, o inimigo mortal que ameaça a Democracia é a indiferença e a passividade do cidadão, a impotência dos indivíduos frente ao universo kafkaniano do poder transverso do Estado Constitucional Modemo e do poder insensível do mercado e da economia.

Percebe-se que, neste contexto complexo, há quem trate de buscar diagnósticos mais ou menos definitivos e soluções de emergência, que operam, não raro, a partir da simplificação arbitrária do complexo. Sempre surgem comentaristas e interessados que, dispostos a ignorar a magnitude e o alcance de muitos dos problemas, encontram fáceis receitas milagrosas ou fórmulas salvadoras capazes de regenerar o edifício da Democracia Representativa.

Sendo assim, para evitar o erro de simplificar arbitrariamente o complexo, sem cair na armadilha de complicar arbitrariamente o simples, o que se tem procurado fazer, por meio deste artigo, é analisar o impacto de todo esse conjunto de transformações históricas sobre o modelo de representação política e sobre o modelo do próprio Estado Constitucional Moderno, tendo como hipóteses a insuficiência de ambos os figurinos 
políticos.

O longo período de estabilidade vivido no pós Segunda Guerra Mundial começou a ver-se afetado a partir da década de oitenta, por um discurso mais ou menos difuso de "mal estar civil", pelo qual, de maneira ambígua, foram projetados diversos tipos de argumentos críticos contra o sistema representativo vigente: desde um certo sentido de "apoliticismo" difuso, conectado com o apogeu da Sociedade Civil, de um "regeneracionismo" mecanicista de viés utópico, de uma lógica sensação de marginalização de certas minorias ou grupos de opinião, até demandas não concretas de um maior controle sobre a política.

Pode-se especular, então, que o grande desafio para o século XXI será a construção de uma Sociedade Democrática Global, respeitadora das diferentes concepções humanas, baseada na paz, na preservação da vida, na justiça social, no acesso de todos ao bem-estar ${ }^{30}$. O objetivo será construir um modelo de organização social, política e jurídica que supere e substitua o atual modelo de exclusão e de concentração de riquezas, denominado Estado Constitucional Moderno, por um outro modelo de Poder Público, Democrático, capaz de tornar realidade esses desejos. Não sendo assim, seria, então, um Estado que nenhum democrata poderia mais tolerar ${ }^{31}$.

Por isso, é preciso, antes de qualquer coisa, que a comunidade científica dedicada à ciência e à teoria do Estado esteja - pelo menos boa parte dela - de acordo com a tese da necessidade de se teorizar uma alternativa ao Estado Constitucional Moderno e à Democracia representativa. Antes disso, qualquer proposição será tida como devaneio e acusada de ingênua, romântica, utópica, etc.

Na tentativa de rever a teoria de Estado, alguns doutrinadores insistem em refundar o Marxismo e o Anarquismo, que padecem dos mesmos anacronismos que acometem o Estado Constitucional Moderno e a Democracia Representativa. Foram, se pode dizer, reações ao Estado Constitucional Moderno. E, assim, acabam sendo o próprio espectro antitético do Estado Constitucional Moderno em uma relação dialética.

O Estado, lato sensu, é importante sempre ressaltar, como Poder Público, não está em causa. Tanto é assim que, como se poderá perceber adiante, parte-se sempre da hipótese da existência futura de uma organização destinada a exercer o Poder Público. Assim, a caracterização clássica do Estado, como existência de população, governo e capacidade decisória e autônoma, e não mais soberana, estará hígida, o que nos impele a olhar. Olha-se na direção do Poder compartilhado, globalizado, com um capitalismo sociatista democrático, um Estado Transnacional. Estas questões levantadas são fruto de constatações científicas, que permitem a base para uma teoria sobre a superação do Estado Constitucional Moderno ${ }^{32}$.

Os elementos que se podem recolher da doutrina mais avançada sugerem que é preciso ser produzido intenso debate teórico sobre a possibilidade de superação de algumas das categorias secularizadas da modernidade: Liberalismo, Socialismo, Capitalismo Liberal, Welfare State, Social-Democracia. Todas estão contaminadas pelo conjunto de teorias que idealizaram o Estado Constitucional Moderno e a Democracia 
Representativa.

Deste conjunto, deve-se chamar atenção para o Capitalismo Liberal. Ele sim é o vírus contaminador de todo o modelo denominado Estado Constitucional Moderno. A crise financeira internacional, que provavelmente matará milhões de pessoas por suas conseqüências, não pode ser combatida eficazmente pelos instrumentos disponíveis atualmente. A complexidade mandarinesca do sistema financeiro internacional desorienta os setores produtivos, enquanto as reações espasmódicas dos tomadores de decisões do govemo contribuem para a sensação prevalente de anarquia. $O$ sistema político, ziguezagueando erraticamente de dia para dia, complica enormemente a luta de nossas instituições sociais básicas para a sobrevivência.

As últimas duas décadas do Século $X X$ e a primeira do Século XXI vêm registrando um estado de profunda crise mundial. É uma crise complexa, multidimensional, cujas facetas afetam todos os aspectos de nossa vida - a saúde e 0 modo de vida, a qualidade do meio ambiente e das relações sociais, a economia, a tecnologia e a política ${ }^{33}$. É uma crise de dimensões intelectuais, morais e espirituais. Uma crise de escala e premência sem precedentes na história da humanidade. Pela primeira vez, temos que nos defrontar com a real ameaça de extinção da raça humana e de toda a vida no planeta.

O ecossistema global e a futura evolução da vida na Terra estão correndo sério perigo e podem muito bem resultar num desastre ecológico em grande escala, como acontece agora com a economia global. A deterioração de nosso meio ambiente tem sido acompanhada de um correspondente aumento nos problemas de saúde dos indivíduos $^{34}$. Enquanto as doenças nutricionais e infecciosas são as maiores responsáveis pelas mortes no Terceiro Mundo, os países industrializados são flagelados pelas doenças crônicas e degenerativas apropriadamente chamadas de "doenças da civilização", da civilização do Estado Constitucional Moderno.

É por se prever um futuro assim tão caótico que faz-se urgente o investimento em uma proposta inovadora como a que seguirá.

\section{A Transnacionalização}

O problema maior da economia - e das finanças - globalizada, derivado das entranhas da modernidade, emerge da base da sua filosofia de liberdade política: emerge do capitalismo e do liberalismo econômico, como anota Friedrich Müller ${ }^{35}$. Temse a sensação de que se está saindo de um ciclo político que dominou os últimos dois séculos, mas a falta de alternativa está levando o mundo a uma crise financeira sem precedentes; e não há evidências capazes de sugerir, ainda, quais serão os termos futuros da confrontação política ${ }^{36}$. 0 espaço ainda não explorado pela política e criado pela mundialização do capitalismo demonstra a necessidade de um locus de poder público entre os estados nacionais.

Nesse sentido é importante destacar a proposta do sociólogo alemão Ulrich 
Beck $^{37}$ com relação à substituição das relações "internacionais" de conflito e/ou disputa por relações "transnacionais”' de solidariedade e cooperação.

O autor alemão aponta que a "globalização" põe o tema da compreensão e organização da Sociedade novamente na ordem do dia dentro do debate público, e isto com uma urgência que não se conhecia desde o marxismo e as disputas sobre a luta de classes.

Em outras palavras, a sociedade mundial, formada a partir da "globalização" promovida pela hegemonia capitalista consolidada a partir de 1989) remete a um "mundo novo", uma espécie de continente não investigado que se abre a uma terra de ninguém transnacional, a um espaço intermediário entre o nacional e o local. Como conseqüência, Beck indica o surgimento de uma faixa de ação própria das sociedades mundializadas. Isso pode ser percebido na relação dos estados nacionais com as empresas multinacionais, o que acaba vinculando um possível futuro Direito Transnacional. Essa previsão se justifica pela persecução da criminalidade transnacional, pelas possibilidades de realização de uma política cultural transnacional, pelas possibilidades de ação dos movimentos sociais transnacionais, entre outros.

O conceito de Estado Transnacional, trazido por Beck, é uma das alternativas possíveis ao fenecimento do Estado Constitucional Moderno e à crise financeira internacional. Beck aponta ainda que há uma racionalização subjacente: o Estado Constitucional Moderno está não só antiquado, mas também é irrenunciável como espaço público garantidor das políticas internas e internacionais de transição, o que o regulará "transnacionalmente" e configurará politicamente o processo de globalização.

Não há dúvidas de que hoje se está diante de uma formidável crise das bases teóricas do Estado Constitucional Moderno, agravada pelo colapso das finanças globais, crise que pode traduzir-se (ou que já se traduz) em aumento do nível de rejeição das instituições por parte dos cidadãos ${ }^{38}$. É justo perguntar-se, já que uma possível via de saída vem indicando uma integração entre as diversas tendências teóricas que tratam do futuro do Estado no ambiente globalizado, se as tecnologias de informação - permitindo, tecnicamente, uma associação mais imediata dos cidadãos nas fases da proposta, da decisão e do controle - podem ajudar-nos a propor, teoricamente, o necessário espaço público transnacional do século XXI.

Parece claro que o capitalismo globalizado vai fazer de tudo para atenuar a atual crise financeira, sempre impondo maiores sacrifícios aos menos abastados. Mas, mesmo que haja êxito, as seqüelas serão muitas e grandes. Desemprego, aumento da pobreza e da miséria, intensificação da concentração da riqueza, mais degradação do meio ambiente, entre outras.

Os espaços públicos - e, por conseqüência, o possível futuro espaço público transnacional - ou é de interesse de todos e pertence a todos ou não faz sentido. Ou o excluído - que tem direitos como todos e deve ser considerado em todas as atitudes e movimentos - tem a ver com a mundialização econômico-financeira (e, mais uma vez, com o espaço público transnacional), ou se estará desenvolvendo um puro diletantismo, 
que interessará apenas às empresas multinacionais, descompromissadas com o equilíbrio vital do planeta. Este é o grande desafio: possibilitar a esses excluídos se reconhecerem e atuarem como cidadãos globalizados. Que o local e o global se complementem.

Para isso, a Democracia Econômica deve servir, antes de tudo, para que a Sociedade evolua, para que a diversidade de opções políticas e não políticas (culturais, relacionais, territoriais, sindicais, étnicas, de idade, etc.) possa se movimentar o mais livremente possível, enriquecendo a complexidade da comunidade ${ }^{39}$. Isto implica diversos mecanismos e instrumentos de validação, adaptados às peculiaridades de cada iniciativa, segundo o âmbito e o momento determinado. Os movimentos livres de iniciativas culturais e sociais definem melhor uma Democracia que quer avançar, sem o jogo moderno da soberania do Estado Constitucional, que tende a bloquear iniciativas discrepantes.

\section{A Democratização do Capitalismo Global - Comentários Finais}

A democratização do capitalismo é condição fundamental para qualquer possibilidade de se impedirem novos desastres financeiros globais que possam corroer ainda mais a combalida qualidade de vida no planeta.

A economia está destinada a produzir riquezas. A política se dedica, ainda que nem sempre seja assim, à distribuição ou re-distribuição destas riquezas. $E$ são as distribuições as que podem ser declaradas de direita ou de esquerda. Mas, em todo caso, a política pode distribuir riqueza somente se a economia a produz. Se a economia não funciona, a política já não tem nada que redistribuir e acaba por distribuir pobreza. A autonomia e prioridade da produção da riqueza, sobre a distribuição, é procedimental. Pode-se, muito bem, dizer que a distribuição é mais importante que a geração da riqueza. Mas a prioridade procedimental continua sendo a mesma. Caso não tenha o que comer, só se pode dividir a fome. E essa não é uma opção interessante.

Assim, considerado o procedimento lógico descrito acima, concebido por Giovanni Sartori $^{40}$, o que resta é a democratização do capitalismo, ou seja, que a comunidade possa participar da decisão do que e como será produzido, e do como e onde será distribuído, principalmente pelo acesso ao crédito, através de políticas publicas distributivas e através de um sistema tributário transnacional, cujo conceito e caracterização serão objeto de artigo científico futuro.

Em princípio, uma economia de mercado é compatível com qualquer sistema político que conceda liberdade ao mercado. Portanto, teoricamente, mercado e ditadura podem acoplar-se, como já se observou durante as ditaduras sul-americanas das décadas de 70 e 80 . Mas está claro que a realidade hoje é outra ${ }^{41}$. Não há como escapar do "contágio democrático", o que torna, na atualidade, praticamente impossível aquele acoplamento. A vitória da Democracia como princípio de legitimidade permite prever que o êxito do mercado se converterá, cada vez mais, numa demanda da 
Democracia. Com a condição, bem entendido, de que o mercado tenha êxito e de que verdadeiramente produza Bem Estar.

As democracias representativas atuais estão carentes de uma estrutura ética concebida a partir de valores democráticos conectados com as necessidades da Sociedade globalizada. Os valores que foram impostos são os valores do mercado, enquanto que o modelo de conduta é o das estratégias empresariais que se movem pelo lucro, deixando de lado outros padrões éticos e de valores totalmente indispensáveis para a convivência, como são os da gratuidade e da generosidade ${ }^{42}$. Assim, a única política possível parece ser a da lógica que o sistema econômico proporciona. Esta colonização da vida pública pela economia fez com que os estatutos de defesa do consumidor (e sua lógica) fossem se afirmando sobre os direitos de cidadania, supondo a mercantilização da vida política, que fica eclipsada. Deve-se recordar, nesse sentido, que o mercado, mesmo com a pretensão descabida de ser um dos paradigmas da liberdade, produz desigualdade e não ajuda a configurar o exercício responsável da liberdade. Isso ocorre porque o mercado, ao proporcionar modelos de discussão privados em lugar de públicos, impede as pessoas de falarem como cidadãs sobre as conseqüências de nossas ações em comum.

O conceito de 'bem comum" passou para a história. Hoje prevalecem os interesses particulares, parciais, o que tem muito a ver com a progressiva tendência de se estruturar o sistema de representação de interesses através de organizações especializadas ou competências estruturadas em torno de critérios setoriais ${ }^{43}$. Isto, junto à própria incapacidade transnacional intrínseca da máquina estatal, vem ajudando a debilitar a capacidade de resposta do Estado Constitucional Moderno ante a cidadania.

Alguns recentes e importantes debates, que estão acontecendo principalmente no plano acadêmico, do qual estão participando teóricos do pós-liberalismo até autores como Robert Dahl ${ }^{44}$, que em seu livro La democracia y sus críticos, reclama uma "terceira transformação" na Democracia, ou seja, o desenvolvimento de uma 'Democracia avançada", capaz de levar os métodos e procedimentos da Democracia à esfera econômica.

Caso isso não seja providenciado, a magnitude das dificuldades econômicas que afetam, na atualidade, tantos países, terá inevitáveis conseqüências políticas. Haverá um agudizamento dos antagonismos sociais de todo tipo, intensificando a luta pelo bem estar econômico e fazendo mais insuportável o custo da derrota. Haverá estímulo da migração econômica ${ }^{45}$ o que, por sua vez, poderá suscitar, nos países mais desenvolvidos, a hostilidade contra os imigrantes e a exigência de que o Estado se converta numa fortaleza ${ }^{46}$. Como se vê, a depressão econômica torna muito mais difícil a consecução do ideal de igualdade cidadã e provoca uma perda de confiança na capacidade dos governos democráticos para solucionar problemas sociais ${ }^{47}$. Os sistemas democráticos mais robustos podem, talvez, resistir a estes choques, enquanto que as democracias mais recentes, que necessitem de panorama mais favorável para consolidar-se, podem sofrer danos irreparáveis. 
Não deverá ser surpresa, portanto, se em futuro próximo for discutida a criação de espaços públicos entre os estados e que aqueles perpassem estes, a fim de regular e democratizar os mercados, tornando-os distribuidores de riquezas. Em tal sentido, a criação de novas instituições transnacionais mundiais democráticas - capazes de regular e controlar com efetividade a atividade econômica e financeira dos mercados deverá ajudar a ajustar a padrões humanitários esse grande cassino em que se converteu $o$ atual mercado financeiro.

As desigualdades em todo o mundo chegaram a proporções sem precedentes. Somente vinte por cento da humanidade usufrui as riquezas, enquanto oitenta por cento vive em condições muito precárias.

Para se alcançar um mínimo de justiça social é preciso, portanto, que se teorizem - e em seguida se apliquem - instrumentos de governança transnacional sobre a produção global e sobre o sistema financeiro transnacionalizado, sendo este um primeiro passo necessário para uma redistribuição radical de riqueza e poder. E é importante anotar que só a redistribuição da riqueza não seria suficiente. Seria preciso considerar a adoção de novas relações de classe e propriedade, fora e além daquelas teorizadas pela modernidade. $O$ local e as relações de propriedade têm implicações globais. Redes de interdependência ligam o local ao global.

\section{THE GLOBAL FINANCIAL CRISIS, THE STATE AND ECONOMIC DEMOCRACY}

\section{ABSTRACT}

The problems the world is experiencing nowadays, particularly the serious global financial situation, are another clear sign of the inadequacy of the modern theoretical model. They might reflect a crisis in the Modern Constitutional State itself. Some recent examples, such as the complex of global food industries which has destroyed traditional seeds and has ended up creating a situation of food imbalance on the planet, the petroleum commercialized worldwide, the communications monopoly, and the manipulable virtual reality, demonstrate that the "internalization" of the Public Power of modernity will probably give way to a transnationalization of this same Public Power. Rethinking Democracy at this time, particularly in its transnational aspect, is essential. The whole "awakened" world, affected by globalization, is increasingly certain that the only legitimate power is that in which investiture is decided by the majority, based on effective democratic instruments.

Keywords: Democracy. Financial Crisis. Modern Constitutional State. Transnationality. Transnational State. 


\section{NOTAS}

Doutor em Direito pela Universidade de Alicante, Diretor do Programa de Doutorado em Direito Ambiental e primeiro diretor do Mestrado em Direito Ambiental e da Sustentabilidade da Universidad de Alicante. Professor visitante da Universite de Limoges, na França, da Universidade do Vale do Itajaí - UNIVALI, no Brasil, e da Universidad Autônoma Metropolitana do México. Membro da Academia de Direito Ambiental e da Comissão de Direito Ambiental da UICN. É Vice-presidente da European Environmental Law Assotiation. (gabriel.real@ua.es)

2 Pós-Doutor em Direito do Estado Pela Universidade de Alicante, na Espanha, Doutor em Direito do Estado pela Universidade Federal de Santa Catarina e Mestre em Instituições Jurídico-Políticas também pela Universidade Federal de Santa Catarina - UFSC. Coordenador e professor do Programa de PósGraduação Stricto Sensu em Ciência Juńdica da Universidade do Vale do Itajaí - UNIVALI em seus programas de Doutorado e Mestrado em Ciência Jurídica. Foi Secretário de Estado em Santa Catarina e Vice Reitor da UNIVALI. É professor visitante nas universidades de Alicante, na Espanha e de Perugia, na Itália. (pcruz@univali.br)

Especialmente na obra La sociedad del riesgo global: amor, violencia y guerra, cuja citação completa encontra-se na bibliografía deste artigo.

4 Sobre o Interesse da Maioria, ver o artigo Sobre o princípio republicano - about the republican principle, de Paulo Márcio Cruz, publicado em http://vlex.com/vid/principio-about-the-principle-45092232.

5 OIT prevê 20 milhões a mais de desempregados devido à crise financeira. Folha de São Paulo. Jornal. 20/10/2008.

6 Em especial, cabe lembrar aqui os esforços para estabelecer uma Autoridade Ambiental Mundial vinculada à Organização das Nações Unidas.

7 CRUZ, Paulo Márcio. Sobre o princípio republicano - about the republican principle. p. 1-10.

8 CRUZ, Paulo Márcio \& CHOFRE SIVENT, José Francisco. Ensaio sobre a necessidade de uma teoria para a superação democrática do estado constitucional moderno. p. 41-62.

9 NUTI, Domenico Mario. Democrazia economica: mercato, política econômica e participazione. p. 123.

10

Importante destacar, nesse sentido, o esforço doutrinário no âmbito do Direito Ambiental está sendo realizado para conceituar e difundir a noção de "Cidadania Global".

CARRIERI, Mimno. No hay democracia sin democracia econômica. p.21.

FUKUYAMA, Francis. The end of history and the last man. p.146.

A situação social era grave e o nível de insatisfação popular tão grande que o povo francês foi às ruas com o objetivo de tomar o poder e arrancar do governo a monarquia comandada pelo rei Luis XVI. A Revolução Francesa foi o mais importante marco da Era Moderna. Significou o fim do sistema absolutista e dos privilégios da nobreza. A Pós-Modernidade significará o fim dos privilégios dos beneficiários dessa mesma revolução e deverá ser levada a efeito, espera-se, por métodos muito mais avançados e civilizados.

A Organização para Cooperação e Desenvolvimento Econômico - OCDE é um órgão internacional e inter-governamental que reúne os países mais industrializados. Por meio da OCDE, os representantes se reúnem para trocar informações e alinhar políticas com o objetivo de potencializar seu crescimento econômico e colaborar com o desenvolvimento de todos os demais países membros. A OCDE não constitui foro de negociação político-diplomática, mas sua atuação no aspecto normativo vem adquirindo importância crescente. Esse fato é particularmente significativo, pois a OCDE representa, por meio de membros, cerca de $65 \%$ do PIB mundial. Soma-se a isso a agilidade decisória da Organização, para concluir-se que tal foro se credencia como um dos focos privilegiados para a tomada de decisões relativas à economia mundial, em seus mais diversos aspectos. 
Sobre isso ver Transnacionalidade e a emergência do estado e do direito transnacionais, de Paulo Márcio Cruz e Zenildo Bodnar, no prelo e que será publicado ao longo de 2009.

HUNTINGTON, Samuel P. Choque de civilizaciones?p. 34.

JÁUREGUI, Gurutz. La democracia planetária. p. 45.

Efetivamente, a solidariedade, no sentido de vínculo social, é um requisito imprescindível para a conformação de um espaço público transnacional, já que "a solidariedade a ação dispersa em ação coletiva, o privado em público", como se expressa Gabriel Real Ferrer, no artigo $A$ solidariedade no Direito Administrativo, publicado na Revista de Administração Pública (RAP), n 161, em 2003, p. 123 a 179.

SANTOS, Boaventura de Souza. Pela mão de Alice: o social e o político na pós-modernidade. p. 277. PETRAS, James. Neoliberalismo: América Latina, Estados Unidos e Europa. p. 359.

MIGLINO, Arnaldo. Democracia não é apenas procedimento. p. 20.

MÜLLER, Friedrich. Que grau de exclusão social ainda pode ser tolerado por um sistema democrático? $\mathrm{p}$. 38.

A Organização das Nações Unidas - ONU, define a exclusão social como a "escassez crônica de oportunidades e de acesso a serviços, ao mercado de trabalho, ao crédito, a infra-estruturas e a justiças. PORRAS NADALES, Antonio. El debate sobre la crisis de la representación política. p. 12-13.

MÜLLER, Friedrich. Que grau de exclusão social ainda pode ser tolerado por um sistema democrático? $\mathrm{p}$. 16.

CRUZ, Paulo Márcio. Chofre Sirvent, Jose Franscisco. Ensaio sobre a necessidade de uma teoria para a superação democrática do estado constitucional modemo. p. 41-62.

CAPRA, Fritjof. $O$ ponto de mutação. p. 19.

CAPRA, Fritjof. $O$ ponto de mutação. p. 22;

MÜLLER, Friedrich. Que grau de exclusão social ainda pode ser tolerado por um sistema democrático?p. 45.

DAHRENDORF, R.; FURET, F. e GEREMEK, B. La democracia en Europa. p. 120.

BECK, Ulrich. Qué es la globalización? Falacias del globalismo, respuestas a la globalización. p. 153.

BERGALLI, Roberto e RESTA, Eligio. Soberanía: un principio que se derrumba. p. 34.

VILLASANTE, Tomas R. Las democracias participativas. p. 136.

SARTORI, Giovanni. La democracia depues del comunismo. p. 98.

SARTORI, Giovanni. La democracia depues del comunismo. p. 25.

OLLER I SALA, M. Dolors. Un futuro para la democracia: una democracia para la gobemabilidad mundial. p. 18.

OLLER I SALA, M. Dolors. Un futuro para la democracia: una democracia para la gobemabilidad mundial. p.18.

DAHL, Robert A. Despues de la revolución. p.13.

A União Europeia é, atualmente, a região do planeta com maior fluxo migratório, o que está produzindo divergências entre os países membros na discussão desse problema. Recentemente, o 0 Conselho de Justiça e Assuntos do Interior de 25 de setembro de 2008 aprovou o Pacto Europeu Sobre Imigração e Asilo, que tende a reforçar os controles sobre a mesma. Não se deve esquecer que boa parte do progresso dos países mais adiantados foi possível graças à imigração. Em todo caso, o Século XXI se caracterizará pelos fluxos migratónios.

JÁUREGUI, Gurutz. La democracia planetária. p.38.

BEETHAN, David \& BOYLE, Kevin. Cuestiones sobre la democracia. p.115.

\section{REFERÊNCIAS}

AMIN, Samir. El 50 aniversário de Bretton Woods. Madrid: Alfoz, 1994.

BECK, Ulrich. Qué es la globalización? Falacias del globalismo, respuestas a la globalización. Barcelona: Paidós, 2004. 
XXI, 2006.

. La sociedad del riesgo global: amor, violencia y guerra. 2. ed. Madrid : Siglo

BEETHAN, David \& BOYLE, Kevin. Cuestiones sobre la democracia. Madrid: Catarta, 1996.

BERGALLI, Roberto e RESTA, Eligio. Soberanía: un principio que se derrumba. Barcelona: Ediciones Paidós, 1996.

BOBBIO, Norberto. O futuro da democracia. Lisboa: Fundação Calouste Gulbenkian, 1995.

CAPRA, Fritjof. O ponto de mutação. São Paulo: Cultrix, 1982.

CARRIERI, Mimno. No hay democracia sin democracia econômica. Madrid: Ediciones HOAC, 1998.

CARVALHO NETTO, M. Constituição e Justiça. 2003. Im. J.N. de M. COUTINHO (org.), Canotilho e a constituição dirigente. Rio de Janeiro: RENOVAR.

CRUZ, Paulo Márcio; CHOFRE SIRVENT, Jose Franscisco. Ensaio sobre a necessidade de uma teoria para a superação democrática do estado constitucional moderno. v.11. Itajaí: Novos Estudos Jurídicos, 2006.

CRUZ, Paulo Márcio. Sobre o princípio republicano - about the republican principle. $\mathrm{v}$. 63. Barcelona: Revista de Derecho vLex, novembro de 2008. (http://vlex.com/vid/principio-about-the-principle-45092232).

DAHL, Robert A. Después de la revolución. Trad. Maria Florência Ferre. Barcelona: GEDISA, 1994.

DAHRENDORF, R.; FURET, F. e GEREMEK, B. La democracia en Europa. Madrid: Alianza Editorial, 1992.

FELIZ TEZANOS, José et alii. La democracia post-liberal. Madrid: Editorial Sistema, 1996.

FERRAJOLI, Luigi. Derechos y garantías: la ley del más débil. Madrid, Trotta, 1999.

FUKUYAMA, Francis. The end of history and the last man. Los Angeles, Simon \& Schuster, 2005.

HABERMAS, Jürgen. Más allá del estado nacional. Ciudad de México: Fondo de Cultura Económica, 1998.

HUNTINGTON, Samuel P. Choque de civilizaciones? Madrid: Tecnos, 2003. 
JÁUREGUI, Gurutz. La democracia planetária. Oviedo: Ediciones Nobel, 2000.

MIGLINO, Arnaldo. Democracia não é apenas procedimento. Curitiba: Juruá, 2006.

MÜLLER, Friedrich. Que grau de exclusão social ainda pode ser tolerado por um sistema democrático? Porto Alegre: Unidade Editorial, 2000.

NUTI, Domenico Mario. Democrazia econômica: mercato, política econômica e participazione. Roma: Ceste, 1991

OLLER I SALA, M. Dolors. Un futuro para la democracia: una democracia para la gobernabilidad mundial. Barcelona: CRISTIANISME I JUSTÍCIA, 2002.

PETRAS, James. Neoliberalismo: América Latina, Estados Unidos e Europa. Blumenau: Editora da FURB, 1999.

PORRAS NADALES, Antonio. El debate sobre la crisis de la representación política. Madrid: Tecnos, 1996.

SANTOS, Boaventura de Souza. A escala do despotismo. Coimbra: Revista Visão. 2006.

SANTOS, Boaventura de Souza. Pela mão de Alice: 0 social e o político na pósmodernidade. São Paulo: Cortez, 1995.

SARTORI, Giovanni. La democracia despues del comunismo. Madrid: Alianza, 1993.

VILLASANTE, Tomas R. Las democracias participativas. Madrid: Ediciones HOAC, 2003.

Recebido para publicação 28/03/2009

Aceito para publicação 10/12/2009 